\title{
A Critique of Curricular Designs: Case studies in Hong Kong
}

\author{
(Joan) Chung Sau- Kwan \\ The Hong Kong Polytechnic University, Hong Kong SAR
}

\begin{abstract}
In the diverse educational settings, there are various designs in the curriculum of English language teaching and learning. Is there a perfect approach in the curriculum? This paper is to investigate certain approaches used in different educational contexts. There are merits and demerits in each approach in the curriculum. Nonetheless, it is said that that an integrated approach, a mixed curricular would be the best as it is more flexible for today's needs in society of the 21 century. In this study, an undergraduate course and a doctoral programme are two different educational contexts for the analysis of the curricular design approaches.
\end{abstract}

\section{Introduction}

Curriculum is generally the sum of learnings including the school subjects, topics, learning activities and the educational ends in an institution. Narrowly speaking, curriculum refers to a unit of work lasting for weeks or in a semester, namely a particular subject course. Or it is the whole programme of study in a few years of time (2). Such a difference in curricula would be discussed with relevant educational contexts as in the following:

Overall, there are three major kinds of curriculum models: content, objective and process. More essentially, the mixed-focus curriculum, known as integrated approach, is considered as flexible, which can cater for the changing needs in the educational settings nowadays [4]. Similarly, there are three curriculum development approaches in language teaching and learning: Forward, Central and Backward Design. There is no perfect approach and the three approaches work well in some circumstances [10]. This paper starts with a review and critique of the former two approaches, pinpointing the weaknesses contained; simultaneously, the undergraduate compulsory course 'University English Writing Skills' at the Open University of Hong Kong is the context for illustration. Based on the limitations, there is a review of the backward approach, whose principles are exemplified in the curriculum 'Doctor of Applied Language Sciences' at The Hong Kong Polytechnic University.

\section{Forward design approach}

Conventionally, the forward design has long been widely adopted in plenty of educational settings. It is assumed that input, process and output are in a linear, fixed sequence. It is conservative and described as an official, mandated curriculum [10]. Here, the content to be learnt or transmitted is the main focus for syllabus planning and the objectives may be specified, having no relationship with learning progress and assessment. This is similar to the Content model [4]. Indeed such a traditional approach commences on the subject matter as the goal for syllabus planning [10], which is very common at the undergraduate level.

\subsection{The University English Writing Skills course}

This is a compulsory English undergraduate course for all year one learners in the School of Arts and Social Sciences at the Open University of Hong Kong. The course content is stated for teachers concerned and learners. From the course outline, specific skills such as paraphrasing, summarizing and referencing are the core; features of academic style are included in the academic writings as well. At The Open University of Hong Kong, it is a didactic, transmission mode of teaching style as it is a very huge class size of about 250 in every lecture. This is similar to the Forward design approach.

As such, a transmission mode of teaching is the norm in class. The inevitable consequence is the passive mode of learning and a massive production of passive university learners in class. The lecturers have been dissatisfied with a massive student population in lecture room, commenting the university policy has put the economic priority at the expense of the overall learning progress and varied needs of students. The varying learning styles and mixed abilities of learners 
are not taken into consideration [4]. Indeed, I did an action research investigating learners' perceptions towards the course before. Their major negative feedback is the boring mechanical lectures, which are merely a presentation of some rules without any involvement with learners. They further mentioned it was not beneficial for their own learning, nor was it motivating for them. Also, the summative assessment based on norm-referencing means that students' academic results merely conform to a pre-set distribution, without any indication of how much progress they have made [10]. After all, this approach is an oversimplification of teaching and learning, without considering the learning process and outcomes.

The forward approach is largely influenced by Chomsky's linguistic theory--Universal Grammar. He advocated the presence of an innate universal grammar explaining why L2 learners acquire language through mastering some sets of rules and words systematically. Language is then regarded as static, individual system and results in the prevalence of transmission mode of learning in class [3]. The defect of the approach is that the essential learning process is totally neglected. It is indeed a genuine and significant component in enhancing the English language proficiency. Oppositely, there is a sociocultural perspective on language learning including Bruner's ideas [1], placing prominence on the social, dynamic and collaborative dimensions in learning [13].

\section{Bruner's Agentive mind \& model of curriculum}

In teaching contexts, teachers need to be concerned with learners' minds in order to understand how learners learn. To a very great extent, I support Bruner's model of agentive mind created in 1996. Accordingly, the mind is active, constructive, and problem-oriented. It seeks out the dialogue with other active ones, coming to know other's view and the world through collaboration and negotiation. In his view, it is learners who construct knowledge actively and purposefully in the process of learning [1]. This perspective is in contrast to the conventional one-way transmission of teacher-talk, in which learning relies on receiving knowledge passively from teachers only.

Indeed Bruner [1] advocated the construction of a curriculum should be a reflection of the fundamental principles of various fields of inquiry. Some major principles include developing a process of inquiry method, conducting open-ended discussion where learners can express and exchange their views, as well as relating their learning to their personal experiences. Thus there are changes in the roles of teachers. No longer being an authoritative figure, the teacher becomes a resource or even cast himself as a learner.
Teaching is not only through instruction but more essentially, via the discovery methods [12]. The principles are reflected in the central approach.

\section{Central design approach}

Unlike the teacher-centered forward approach, the Central design approach is very much concerned with the learning processes where the emphasis is on active learning and deep understanding. Learners are given room to develop cognitive growth and cultivate further independent learning mode in future [4]. The starting point is the classroom activities, techniques and methods involving the negotiation of meanings through interaction, replacing the traditional didactic mode [10]. The essence of a curriculum enactment is what happens in classroom, and the interrelated, dynamic relationship among a teacher, students and the subject matter [7].

\subsection{Merits of Central design approach}

Viewing the above, a learner-centered curriculum or a learning curriculum is on the spot. The features of central design are the essence of the process model, such as the focus on methodological principles and procedures to guide the teaching process rather than emphasizing on the initial specifications of the objectives or specified syllabus [10]. Unlike the Forward design approach, the strength is the changes in the roles of the teacher and learners. The teacher plays the role of a facilitator for learners' learning activities in classroom contexts, whilst the learners can be more active through engagement in class. Even more, they are more responsible for their own learning; the independent mode of learning is strongly encouraged. Formative continuous assessment and self-assessment are implemented, where learners are required to have self-reflection in the learning process [10].

Additionally, one academic value is that the classroom becomes a community of learners and teacher, where the learners can interact and share their learning experiences, thus facilitating their learning progress. Such is in line with Lave and Wenger's [8] view that learning is not merely identified with getting discrete, abstract knowledge. They explained learning is a situated activity, an integral part of social practice in the world. Daily participation is of major concern-learning is doing [8] and passive learning is explicitly denied.

\subsection{The tutorials of 'University English Writing Skills'}

After learning the educational theories from Bruner, Piaget, Vygotsky, Lave and Wenger, my tutorials have been revolutionized. Endorsing their 
views, I added teacher-student interactions to stimulate their thinking. Additionally, there were some pair work and group work in class, where learners were required to interact with peers to exchange their perspectives and negotiate meanings. In class, they needed to cooperate to write a short piece of writing practicing paraphrasing and summarizing skills. Also, they need to do some kind of proofreading for their classmates and assess the peers' work. In so doing, they act as the roles of tutoring as well. The positive feedback from my action research is that they did enjoy discussion in class and found learning could be optimized in the interactive tutorials, instead of being passive learners during lecture.

In my tutorials, the essence of central approach is reflected in the provision of learning activities, which are be very crucial learning process. Learning is inseparable from the context [1]. Consequently, my role as a tutor is a facilitator, not confined to instructor and the role of learners is no longer passive learners but active participants and even 'tutors'. Such is very much different from the situations in lecture, where students are passively receivers of knowledge and lecturers are knowledge transmitter. Learners' personal interests as well as active participation are prioritized and learner-centred curriculum is adopted. Such is equal to the Process model [9]. It is also typified by Bakhtin's notion of dialogicality illustrating that language learning is an on-going and dynamic process through which language users are in the process of accomplishing some goals in classroom activities [3]. More importantly, the approach has put more emphasis on understanding learning and helping to improve learners' capacity through participation and negotiation. The by-product examination is not stressed as a legitimate educational goal [12].

\subsection{Demerits of Central design approach}

Notwithstanding the above strengths, the meaningfulness of the learning activity is questioned for the following aspects. First, the approach may not have the explicit purposes for the learning activities and it would be worse if the learning outcomes are non-existent. The classroom activities would be a mess if there is a lack of monitor. The approach lacks the learning evidence from the learners [10]. Regarding the assessment on the learners, it is regarded as subjective and impractical in assessing learners' continuous performance in classroom learning. Despite the presence of the criteriareferenced assessment, there is much criticism that teachers' judgment may vary. All of these can expose the demerits of individual teachers, who may need further professional teachers' development [12].

The emphasis is on the learning contexts, teachers should be experienced and competent in monitoring learners' learning progress. Indeed, teaches should have the knowledge of the educational ends, purposes and philosophy of the institution. Teachers need to be equipped with the pedagogical content knowledge-knowing what and how to teach, providing learners both instruction and learning opportunities. All these should be adapted to meet the learners' motivation, mixed abilities and difficulties learners confronted [11] through employing different strategies to guide learners and to achieve desirable outcomes. Such is compatible with Vygotsky's Scaffolding metaphor remarked in 1978, which has illustrated the appropriate assistance offered from a teacher to the learners in the learning process. Then teachers continuously help the learners to proceed to higher level [14]. All in all, teachers should be equipped with a very high level of professional knowledge, sound educational theories and novel judgment to cope with the practicalities and complexities of classroom learning.

\section{Backward design approach}

In this approach, numerous overall goals and intended learning outcomes of the curriculum are stated, which are the prerequisite for the teaching activities, learning processes and the content. It is also named as 'ends-means' approach and has become a crucial curriculum approach [10]. What is significant is its multi-dimensional nature, encompassing the initial intended outcomes, the need analysis/assessment, specification of objectives, selection of content associated with relevant learning activities and finally the evaluation [7]. As we shall see, the principles of Backward design approach are reflected in the curriculum--Doctor of Applied Language Sciences.

\subsection{Needs assessment at DALS}

Essentially, needs assessment is a very vital component for understanding more about the learners - their educational background, knowledge, abilities and needs. Then the curriculum is to bridge the gap, i.e., addressing learners' needs effectively. For DALS curriculum, applicants' background including culture, educational achievement, professional knowledge and language proficiency are assessed as objective. To evaluate subjective needs, information related to learners' expectations and their main purposes towards the doctoral programme is collected through handling the formal statements around 2000 words and assessment during a formal interview. Besides, items including teachers, administrators, employers and society are taken into account [7]. The needs assessment has emerged as a very paramount component of a curriculum design, which determines the aims and outcomes of a curriculum [10]. 


\subsection{DALS Programme Philosophy, Aims and Objectives}

Goals, objectives and intended outcomes provide the appropriate direction for the content and activities in the course/programme, a framework for teachers' planning [7]. At The Hong Kong Polytechnic University, the motto is to 'To learn, to apply and to administer". The institutional philosophy is important [7], adopted by the DALS programme. DALS graduates are expected to grasp the linguistics theories in the professional contexts or language-related disciplines, understand and integrate the global perspective with the local contexts [14]. In line with the University policy, the DALS programme is aimed at cultivating numerous future leaders capable of applying the linguistic theories into the practical language-related contexts. Learners are encouraged to deepen and broaden their knowledge and research skills, and to have a critical understanding of the knowledge from international perspectives and language-related disciplines so as to survive in the globalized society [14]. These aims are appropriate for meeting the very complex social and economic realities of the changing society in HKSAR, as well as providing a framework for subject teachers' planning.

\subsection{Intended Learning Outcomes at DALS}

At DALS, there are three institutional learning outcomes, in which learners can possess advanced knowledge skills to become a competent specialist in a particular discipline [14] --proficiency goal [7]. Also, learners can have a high level of critical, analytical and creative thinking skills in the subject knowledge and get the solutions to problems encountered in their professions [14] --cognitive goal [7]. The third one is to develop a lifelong independent learning mode, which strives for inquiry and reflection in their professional development [14]-transfer goal [7]. All these types of goals [7] are discerned in DALS curriculum (8 coursework and thesis I and thesis II writing). Besides, there are seven intended learning outcomes, which also act as a framework for the compulsory and elective subjects [13]. It is true to say that real education does need direction and the educational practice cannot be nondirective [5]. My main argument is that the three institutional learning outcomes /goals and the seven intended programme learning outcomes are interrelated with content subjects and classroom activities. To achieve the desired learning outcomes, a variety of instructional strategies are employed [10] as in the following.

\subsection{Instructional strategies at DALS coursework}

In DALS programme, the interactive mode of teaching and learning is highly recommended in all the compulsory and electives courses [14]. The focus is on what the learners do with teachers, peers and the materials, and the learners act as active participants [7]. To achieve the desired learning outcomes, there are many instances of teaching-learning techniques providing ample learning opportunities for attaining the educational ends as in the following.

5.4.1. Curriculum and Assessment. At DALS, for example, in the coursework "Curriculum and Assessment", the interactive lectures with group work help develop teamwork to a certain extent, one of the programme learning outcomes [14]. The teamwork in class, together with questioning from the teacher, help produce lots of dynamics in classroom learning, which is exactly fantastic, exiting and genuine learning. Apart from the visual PowerPoint slides vividly illustrating the concepts and curriculum models, the instances of innovation are discussed in teacher-student or student-student interactions after weekly readings before class. Circular tables, a physical classroom setting, can allow students more easily to interact and discuss the issues and subject matter in class. The features of learner-centred curriculum exist, the advantages of the Central design approach -teachers are a facilitator and students are active participants. In this coursework, class participation occupies 20\%, not a very huge percentage but would encourage students' efforts in preparation before and get involved in the learning activities in class. Such is in line with the explicit description of the teaching-and-learning methods; interaction is very much encouraged at DALS [14]. Through the instructional strategies, an advanced understanding of the curriculum theories related to second language education is enhanced and extended, one of the programme learning outcomes [14]-cognitive goal achieved [7]. I would be more analytical in applying theories to educational contexts, one of the institutional learning outcomes [14] -transfer goal achieved [7]. I am more confident to be a competent curriculum advisor at secondary or tertiary level in the near future, one of the institutional learning outcomes [14]. Positive attitudes towards the subject and having more confidence as a learner are the affective goals [7].

5.4.2. Discourse Analysis and Corpus Linguistics. In 'Discourse Analysis and Corpus Linguistics', the learning activities include student-led seminars and individual presentations, in which learners can express sophisticated academic ideas at doctoral level, also the novel characteristics of the Central and Backward design approaches, and can help attain one of the programme learning outcomes [14]-- 
proficiency and cognitive goals achieved [7]. Also, through doing the small-scale research project, I have learnt to use corpus, appropriate information technology tools as a research method to get primary data and for evidence-based analysis in education area, one programme learning outcome [14]--transfer goal achieved [7]. The content of this coursework is discourse analysis, including multi-model discourse, critical discourse and genre analysis. This coursework also examines corpus linguistics, the corpus approach to genre and discourse analysis. The backbone of the content is stated in the syllabus, another good element of the Backward design approach [7].

5.4.3. Intercultural Communication. In 'Intercultural Communication', learners need to choose and present a particular theory of their preference within 20 minutes and then a 10-min question and answer session at doctoral level in class, demonstrate an understanding of current theories [14] - proficiency goal [7]. Other assignments include writing and evaluating the literature review on a relevant topic and conduct a mini-scale research based on the specific theory, developing a sophisticated understanding of current theory, a programme learning outcome [14] — transfer goal achieved [7] (I examined the intercultural communicative experiences of overseas teachers at university in Canada). Besides, the interactive learning mode is mostly adopted to allow students to interact with peers, the learning materials (research studies) and teachers though this part of learning would not be assessed. Thus learners can learn and have cognitive growth during the learning process and the progress can be made through participation in class. The beneficial point of the Central and Backward design approach is present here.

5.4.4. Professional and Organizational Communication. In 'Professional and Organizational Communication', learners are required to do a case study (i.e. shadowing of a one-day work of a professional in specific industry investigating the English/Chinese communication with colleagues in the workplace). One needs to adopt appropriate research design and method to obtain data from profession-related areas, one programme learning outcome [14] — proficiency goal achieved [7] (I examined the written and spoken communication of a research assistant in my workplace). Similarly, students need to evaluate critically the literature and current trends in some areas of profession and develop an advanced understanding of some issues in professional and organizational communication [14] and conduct a relevant mini-scale research, two programme learning outcomes [14] - proficiency and transfer goals achieved [7] (I investigated the communicative strategies of the Hong Kong Chinese in the lower institutional hierarchy). With all these practice, I can have more experiences and am more confident to conduct large-scale research and more competent in writing journal articles - affective goals [7]. As a whole, the interactive learning mode is encouraged and adopted in class so that students can discuss certain theories, concepts or questions designed from the teachers though no assessment is made in class participation. The learning progress is not ignored but helps to achieve the intended learning outcomes. The good feature of Central and Backward design approaches is present. As indicated, the programme learning outcomes in DALS are achievable to great extent.

5.4.5. Thesis I and II. All the above coursework is a preparation for the more important thesis one and two afterwards at DALS; they are in the appropriate sequence of part-skills to the whole, another merit of backward approach [10]. At DALS after completion of 8 eight coursework, doctoral students need to write a thesis proposal, divided into part one (1000-15000 words of a research proposal) and part two (5000 words of a thesis). In part one, I made use of the previous learning, writing a sophisticated and critical literature review, methodology, incorporated two pilot studies from the coursework and writing up other items such as Introduction and Background in my proposal as well. Thesis 1 oral assessment was done, where the complex ideas are expressed clearly to comply with the academic genre [14]. All these are proficiency, cognitive and transfer goals from the coursework [7]. Having more knowledge and experiences in conducting research, my main study is to conduct research in a foreign country investigating international students and then continue writing up the thesis paper confidently and more easily at DALS proficiency, cognitive, transfer and affective goals [7].

At this moment, I am in the final part of my thesis writing (Part 2). I need to write a very complex literature review in a chosen area, analyse research data in a very detailed and systematic way, with the application of relevant theories and discussion. The written work should be publishable and professional at doctoral level [14]. Later on, I need to present and express the research project in the oral assessment. I would like to say DALS programme is very practical and interesting. Interesting is that students' motivation of learning can be aroused and knowledge increased in class and through weekly readings before, during or after class. Practical is that students' knowledge and competence in research can be further enhanced from assignments (written and oral forms), transforming doctoral students into an independent researcher as a whole. Additionally, some of my coursework assignments can be published overseas one by one currently as they are research-related papers and of high quality. Therefore, the proficiency, cognitive, transfer and affective goals can be achieved at DALS successfully. In the future, I think I am 
competent to be a teacher and a researcher at tertiary level because of my study at DALS. The three institutional learning outcomes: a possession of advanced knowledge and skills in specific area, a high level of analytical and creative thinking in professional application and the capability for lifelong learning and inquiry [14] are achievable.

\subsection{Evaluation}

Furthermore, there are DALS committee meetings called The Student/Staff Consultative Committee, c channel for getting students' views on the programme including the recommendation of new courses, reporting teachers' performance in the coursework via surveys, teachers' report on students' progress and performance in coursework, as well as students' additional feedback on any aspects of the programme. The Committee meetings would be chaired by the Programme Leader, some relevant teachers concerned and student representatives from each cohort are participants. DALS learners can also participate voluntarily. This DALS curriculum is subject to changes for improvement; planning, acting and evaluating are integrated [9].

Regular evaluation via online surveys by the end of one term is done for the sake of teachers and students' benefits. Questions would include if the materials and learning activities appropriate or not for the students, if teachers' role is helpful or not, and students' constructive suggestions for the coursework or teachers concerned [7]. In essence, DALS proceeds through a blending of content and pedagogy, where particular courses and topics are organized by professional lecturers. In classroom, meaningful learning activities are associated with instruction and are adapted in the case of the diverse abilities of learners [11]. All of these are distinguished features of the Backward design approach.

\section{Conclusion}

Curriculum is not confined to either the Forward design approach or the Central approach. The two types of curricula merely imply a conception of learners or learning process [6]. The Backward design approach is to fuse the perspectives together, metaphorically linking different parts of a continent [6]. It is much more preferable and can meet today's needs--learners should be imparted with facts of knowledge, cultivated with skills and understanding. In brief, the Backward design approach is more prominent--an integration of the curriculum approaches. What seems to be certain is, in this approach, important factors such as motivation, aptitude, personality, learner preferences and beliefs, gender and educational attainment are taken into considerations [2].

\section{References}

[1] Bruner, J. (2007) "Folk Pedagogies." In J. Leach \& B. Moon (Eds.): Learners and Pedagogy. London: UK Open University.

[2] Candlin, C.N. and Mercer, N. (2001) English Language Teaching in its Social Context. Milton Keynes: The UK Open University \& Mcquaire University.

[3] Cheng, A.y-m. and Winston, J. (2011) "Shakespeare as a second language: playfulness, power and pedagogy in the ESL classroom." RiDE: The Journal of Applied theatre and Performance, 16(4). London: Routledge.

[4] Finney, D. (2002) "The ELT Curriculum: A Flexible Model for a Changing World." In J.C. Richards and W.A. Renandya (Eds.): An Anthology of Present Practice. Cambridge: Cambridge University Press.

[5] Freire, P. and Macedo, D. (2007) "Pedagogy, Culture, Language and Race: A Dialogue." In J. Leach \& B. Moon (Eds.): Learners \& Pedagogy. London: UK Open University.

[6] Garcia, D. (1976) "Decisions and Variables in Curriculum Construction: Their Implications for Syllabus Design in English Language Teaching." In G. H. Wilson (Eds.): Curriculum Development and Syllabus Design For English Teaching. Singapore: Singapore University.

[7] Graves, K. (2003) "A Framework of Course Development Process." In D. R. Hall \& A. Hewings (Eds.): Innovation in English Language Teaching. London \& New York: Macquarie University.

[8] Lave, J. \& Wenger, E. (1999) "Legitimate Peripheral Participation." In P. Murphy (Eds.): Learners, Learning \& Assessment. London: Open University of London.

[9] Morrison, B. (2015) Doctor of Applied Language Science--Curriculum and Assessment. Lectures 1-3. Hong Kong: HK Polytechnic University.

[10] Richards, J.C. (2013) Curriculum Approaches in Language Teaching: Forward, Central and Backward Design Relc Journal, 44(1), 5-33.

[11] Shulman, L. (2007) "Knowledge and Teaching: Foundations of the New Reform." In Leach, J. \& Moon, B. (Eds.): Learners and Pedagogy. London: UK Open University.

[12] Stenhouse, L. (1975) "A Critique of the Objective Model and a Process Model." In Scott, D (Eds.): Curriculum Studies.

[13] Walsh, S. (2006). Investigating Classroom Discourse. New York: Routledge.

[14] Wu, D. and Mathiessen (2014). Doctor of Applied Language Science Handbook. Hong Kong: The Hong Kong Polytechnic University. 